\title{
CONSUMERS IN A MULTICHANNEL ENVIRONMENT: PRODUCT UTILITY, PROCESS UTILITY, AND CHANNEL CHOICE
}

\author{
SRIDHAR BALASUBRAMANIAN, RAJAGOPAL RAGHUNATHAN, AND \\ VIJAY MAHAJAN
}

\section{SRIDHAR}

\section{BALASUBRAMANIAN}

is Associate Professor of Marketing,

Department of Marketing, The

Kenan-Flagler Business School,

University of North Carolina at

Chapel Hill, NC; e-mail:

balasubs@bschool.unc.edu

\section{RAJAGOPAL}

RAGHUNATHAN

is an Assistant Professor and

VIJAY MAHAJAN is a

Professor, Department of Marketing,

McCombs School of Business,

University of Texas at Austin, TX;

e-mail:aj.raghunathan@bus.utexas.

edu and

vijay.mahajan@bus.utexas.edu

1 e present a conceptual framework that clarifies the utilities that consumers using a channel derive from both the purchase process and the purchased products, and the mutual influences between these process and product utilities. Drawing on interviews with customers, we examine how the following factors influence product and process utilities, and hence consumers' choice and use of channels: (a) their economic goals, (b) their quest for self-affirmation, (c) their quest for symbolic meaning associated with the product and with the shopping process, $(d)$ their quest for social interaction and experiential impact, and (e) their reliance on schemas and scripts for shopping. We examine how these factors may influence channel choice at the following three stages of the purchase process-forming a consideration set, choosing a product, and buying the product. Consumers may navigate between channels when they use distinct channels across these stages. Our analysis yielded implications for researchers examining consumer behavior in the multichannel environment and recommendations for marketing managers operating in that environment.

(c) 2005 Wiley Periodicals, Inc. and Direct Marketing Educational Foundation, Inc.

JOURNAL OF INTERACTIVE MARKETING VOLUME 19 / NUMBER 2 / SPRING 2005

Published online in Wiley InterScience (www.interscience.wiley.com). DOI: 10.1002/dir.20032 


\section{INTRODUCTION}

Consumers display complex shopping behaviors in the emerging multichannel environment, which includes traditional retail stores and the Internet (Alba et al., 1997; Peterson, Balasubramanian, \& Bronnenberg, 1997). Some consumers may use one channel to perform all shopping activities within a product category. Others may rely on different channels at different stages of shopping within a single category. For example, they may search for information online but purchase in a retail store. Predictions that nimble, virtual sellers will replace inefficient brick-and-mortar retailers (see Evans \& Wurster, 1997) are fading as analysts realize that markets of the future will contain a mix of channels.

Researchers have discussed consumer decision making, search, and competition in the online environment (Ariely, 2000; Bakos, 1991, 1997; Brynjolfsson \& Smith, 2000; Hoffman \& Novak, 1996). Comparing online and traditional retail environments, Degeratu, Rangaswamy, and Wu (2000) demonstrated how brand name, factual information (as opposed to sensory information), and price sensitivity gain in importance online. Likewise, comparing consumers who choose hotels online or offline, Shankar, Smith, and Rangaswamy (2003) found that the former had stronger reciprocal links between satisfaction and loyalty.

Research that focuses specifically on consumers' use of multiple channels in searching for and deciding on products is relatively sparse. In an early analysis, Peterson et al. (1997) conceptualized how consumers might navigate a mix of catalog, Internet, and traditional retail channels during various stages of the purchase process, including (a) the preliminary search for information, (b) subsequent search for more detailed information, and finally, (c) product purchase. They projected what navigation paths across channels were likely for various product categories. Alba et al. (1997) analyzed the strengths and weaknesses of the various channels and noted that the presence of multiple channels can help consumers shape their consideration sets efficiently early in the search process. Balasubramanian, Konana, and Menon (2003) and Konana and Balasubramanian (in press) discussed how online investors partitioned their asset portfolios into two components, one that they managed independently using online brokers and one that they invested through human brokers.

Despite these advances, knowledge of consumer behavior and managerial strategies in multichannel environments is sketchy. Researchers and managers need a deeper understanding than currently exists of how, when, and why consumers choose specific channels while shopping. A specific issue that researchers have not tackled in sufficient detail is the choice and use of different channels at various stages of shopping. To further such understanding, we describe how utility from the purchased product and that from the purchase process, and interactions between these two sources of utilities can influence channel usage in the multichannel environment. By separating overall utility into product- and process-related utilities, we derive some counterintuitive insights that would otherwise be less accessible. For example, we will suggest later that the arguably inefficient search and choice processes related to the traditional retail sector can enhance the utility obtained from the purchased product and even from the purchase process under certain conditions.

In analyzing channel choice, we consider the distinct goals consumers pursue during various stages of shopping. Researchers have documented how consumers' orientations towards choice, value, purchase likelihood, brand attitudes, and anticipated satisfaction can differentially affect their preferences (Carmon \& Simonson, 1998; Fischer, Carmon, Ariely, \& Zauberman, 1999; Nowlis \& Simonson, 1997; Shiv \& Huber, 2000). Similarly, consumers' specific goals during stages of shopping will likely influence channel preference. Consumers will use multiple channels within a purchase process when they prefer distinct channels at various stages.

In discussing how consumers choose channels at any stage of the purchase process, we focus on five goals they pursue while shopping: (a) pure economic goalshow consumers' pursuit of efficiency and utility can influence channel choices; (b) self-affirmation-how the opportunity to play out their subjectively perceived expertise can influence channel choices; (c) the quest for symbolic meaning-how the satisfaction consumers anticipate from the effort and attention they expend in shopping can influence channel choices; (d) the quest for socialization and experiential 
impact-how consumers' need to be part of social milieus or of stimulating environments can influence channel choices; and (e) the use of shopping-related schemas and scripts-how the goal of maintaining regularity and familiarity can influence channel choices. In broad terms, these shopping-related goals can be mapped on to the Weberian universal bases of goal-directed action - the affective (based on emotion), the value-rational (based on values), the means-end rational (based on calculation), and the habitual or traditional (based on habit).

We introduce the conceptual framework next. We then discuss how channel choice may occur at various stages of the purchase process. We conclude with a discussion of the managerial and research implications of our arguments.

\section{CONCEPTUAL DEVELOPMENT}

We based our conceptual model on fieldwork that included interviews with over 30 customers who were active in online and/or traditional retail environments. We also interviewed customers who purchased services (for example, travel services) through online brokers and service providers, human brokers and service providers, or both. These interviews provided a practical perspective regarding channel choice and helped us demarcate some of the important but less obvious influences that drive channel choice. We use stylized vignettes to clarify some of the concepts related to shopping behaviors that we have observed or that interviewees have described.

\section{Influences on Channel Choice Decisions}

Consumers' use of a channel (or channels) in a shopping process must be considered in light of the final outcome (often, but not always, the purchased product) and in light of the process of using the channel (or channels). This dichotomy between outcome and process is theoretically well known. It parallels the distinction of culminative versus comprehensive outcomes (Sen, 1997) and distributive versus procedural fairness (Colquitt, 2001).

The total utility associated with the use of a channel at any stage of the purchase process has three components. First is the utility from the instrumental elements of the process that are central to the purchase of the product. Activities that entail physical effort (for example, driving to the retail store, picking products and replacing them on shelves, and pushing the shopping cart) and activities intended to assess the quality of products (for example, hefting and smelling produce) constitute instrumental elements. Online and traditional retail channels differ in terms of such instrumental elements. Traditional retail shopping generally requires greater motor effort and, for most products, affords richer opportunities for assessing product quality. These elements of the purchase process can directly affect the attractiveness of the channel (it may allow consumers to explore interesting product categories or to pleasurably play out their expertise at product selection) and can affect the attractiveness of the product or products chosen using the channel (consumers may be pleased with specific products at specific stores that appear to suit their needs or to be good deals). Online, the instrumental elements of purchase consist mainly of searching and comparing offerings across Web sites-the effort consumers expend could vary with their experience with computers and Web sites (Figure 1).

Second is the utility from the product itself. This component of utility may be driven by the instrumental elements of the purchase process. For example, a teddy bear a consumer carefully selected as a gift after painstakingly searching the aisles in a large toy store is likely to have a special appeal to the purchaser; it is not just another teddy bear.

Third is the utility from the noninstrumental elements of the shopping process, elements that are peripheral to the shopping expedition and occur during the shopping process but are not necessarily central to the tasks associated with acquiring information, evaluating, and choosing products. Under certain circumstances, however, the noninstrumental elements of the shopping process may assume greater importance than the instrumental elements. For example, when consumers view shopping expeditions as opportunities to relax or socialize, the objective of purchasing within a certain product category may be a less important driver of channel choice than the atmospherics of the shopping environment (that is, the nature and intensity of nonproduct stimuli). 


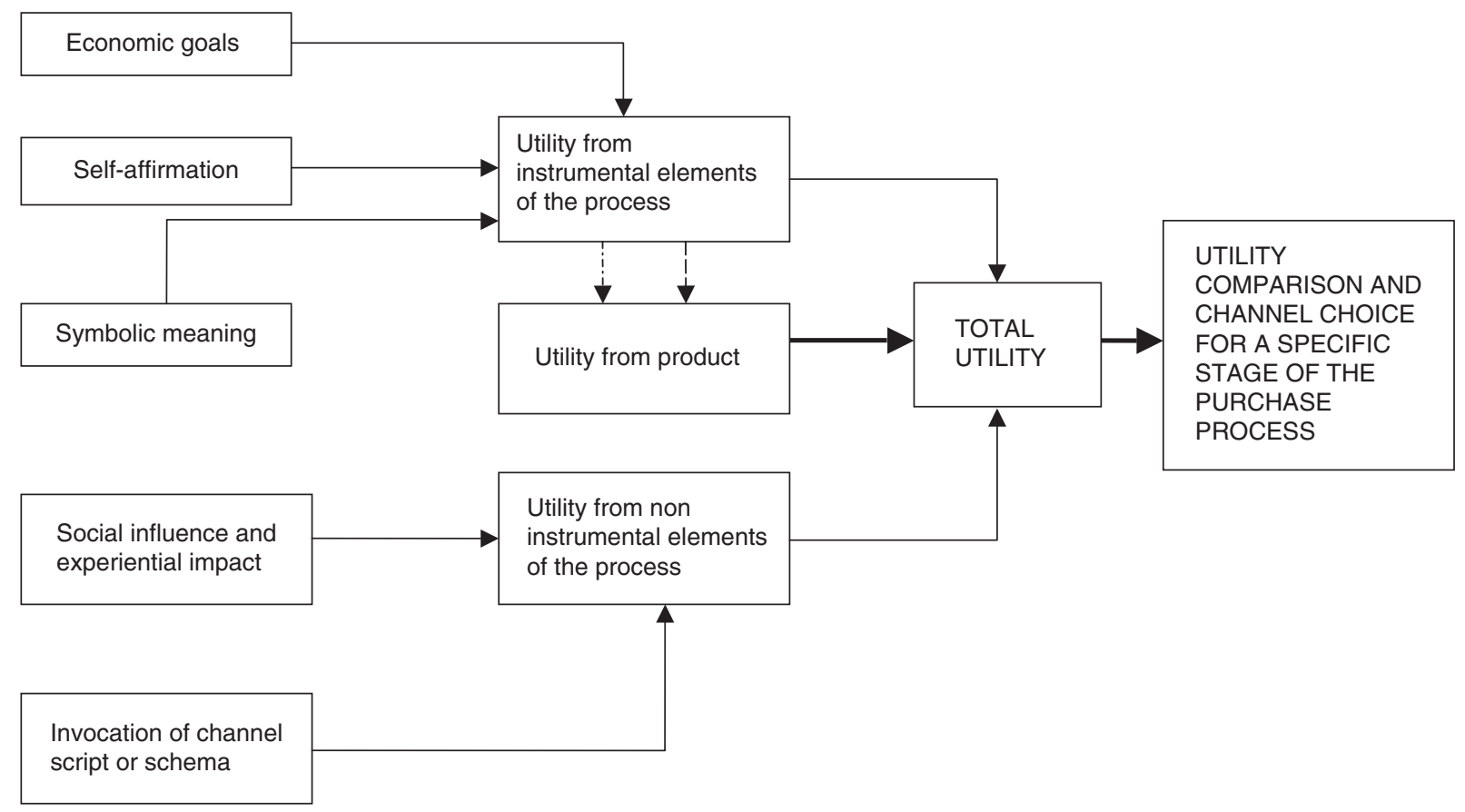

\section{FIGURE 1}

Determinants of Channel Choice at a Given Stage of the Purchase Process

We posit linkages among these three sources of utility and certain antecedents. For the utility from instrumental elements, pure-economic motivations constitute the first antecedent. Many shopping behaviors are driven by the consumers' quest for convenience, efficient information gathering, and the best value. The second antecedent is the consumers' quest for self-affirmation. For example, by hefting, smelling, and carefully inspecting oranges before placing them in their shopping carts, shoppers can affirm their expertise in evaluating and selecting oranges. The third antecedent is the quest for symbolic meaning. For purchases with symbolic meaning (for example, gifts for family members), channels that require greater effort may imbue products procured with greater symbolic meaning, and consequently greater utility, than those that involve less effort. Such symbolism may also render the shopping process itself more meaningful and rewarding.

For utility from noninstrumental elements, the first antecedent is the shopping environment, which may include social and experiential influences. The second is use of a channel that is caused by the consumer's triggering of a channel-related schema or script. The importance of different factors can vary according to the stages of the purchase process-these stages are described next.

\section{The Stages of the Purchase Process}

The purchase process, at least for products that require medium to high involvement on the part of consumers, consists of distinct stages (Lilien, Kotler, \& Moorthy, 1992). Researchers agree that consumers form consideration sets, usually consisting of about five products, early in the purchase process (Nedungadi, 1990). Then, based on further evaluation of the products in their consideration sets, they select particular products (or sets of products) for purchase.

We identified factors that influence channel choice in each of three stages in a typical purchase process: (a) forming a consideration set, (b) choosing a product, and (c) buying the product. Consumers' objectives influence their choice of channels, and their objectives may differ by stages. We next discuss the key goals that may be relevant in the context of shopping, and how those goals may influence channel choices at the three stages discussed above. 


\section{ECONOMIC GOALS AND CHANNEL CHOICE}

Vignette 1: Harold Shapiro considers shopping a distraction to be minimized. He does as much of his shopping online as possible. He tries to restrict his nongrocery retail shopping to just a few occasions a year. He plans these occasional retail expeditions, usually involving his family, to coincide with the traditional sale days around Christmas and Thanksgiving. The whole family stocks up on clothing for the next year on such occasions.

Harold Shapiro's pursuit of purely economic goals is consistent with models of consumer behavior developed by neoclassical economists. When their goals are purely economic, consumers focus on maximizing net utility, defined as the utility they derive from the good less the total costs of obtaining it, which, apart from price, may include the real costs of travel, the opportunity cost of time, and the implicit cost of inconvenience (Balasubramanian, 1998). A consumer pursuing purely economic goals would base channel choice on a careful trade-off of the costs and benefits of using specific channels at the different stages of the purchase process.

During the first stage, consumers gathering information about many products to form their consideration sets may find the Internet particularly useful. Researchers agree that information-search costs are generally lowest in online channels (Bakos, 1997; Peterson et al., 1997). Multiple Web sites allow consumers to construct tables that can be used to compare products across attributes. Based on such comparisons, consumers with economic goals can use the Internet to apply efficient decision rules, such as the conjunctive or disjunctive rules (Svenson, 1979). Further, the Internet is particularly useful for collecting detailed information about new and technically sophisticated products (for example, expensive home theater systems).

Online channels suffer from a significant limitation, however; they represent product attributes in an impoverished fashion. Whereas consumers can potentially experience all sensory elements (cf. Schmitt \& Simonson, 1997)—sight, sound, taste, touch and smell-in traditional retail stores, they can only infer some of them online. While the sensory capabilities of the online medium are improving, current online environments do not permit average users to feel the texture of a piece of clothing or to smell the interior of a car. If exposure to sensory or experiential (cf. Schmitt, 1999) elements of products is important in forming a consideration set, consumers will prefer traditional retail stores at this stage; otherwise, given that accessing information is easier online (Bakos, 1997), they will likely prefer online channels.

Stated differently, consumers' choice of channel while forming their consideration sets depends on their confidence in their abilities to evaluate products with and without experiential input. When consumers perceive experiential input as likely to increase confidence in their judgments, they may prefer traditional retail stores. However, we believe that two factors are likely to moderate this effect: (a) product categorytype, (b) familiarity or expertise with product category (cf. Alba \& Hutchinson, 1987). By product-category type, we distinguish between products serving functional or utilitarian purposes (for example, memory card for a laptop) or hedonic or emotional purposes (for example, a work of art). Since consumers can convert verbal descriptions of functional features into the associated functional benefits more easily than they can convert verbal descriptions of experiential features into corresponding experiential benefits, they will feel more confident about evaluating utilitarian (vs. experiential) products even without experiencing the benefits. Experiential input, on the other hand, is important for evaluating hedonic products, since it is difficult to convert representations of hedonic attributes (for example, a verbal description of how a car handles) into the associated experiential benefits. With time and experience, though, some consumers may be able to learn the consumption language (cf. West, Brown, \& Hoch, 1997) that allows them to translate nonexperiential information into experiential benefits. For example, they may be able to assess the experience of handling a car based on a description, such as the claim of road-hugging traction even when driving at 60 miles an hour on a sharp 30-degree turn.

In sum, consumers pursuing economic goals are likely to use online channels for forming consideration setsbecause it is easier to compare products in this medium-unless the hedonic dimension is important in the product category, or they have learned the 
consumption language that lets them convert verbal representations of attributes into experiential benefits.

The objective in the first stage of the purchase process is to narrow down the consideration set (by eliminating unacceptable or dominated options). In the second stage, the objective is to select the product(s) that offer maximum utility. Consumers are likely to use different decision rules or heuristics across these two stages (Raghunathan, 2004). Instead of the efficient decision rules they are likely to employ in the first stage, they are likely to use normative rules (such as the linear additive rule) in the second stage to select the best product (or set of products) from the consideration set. Given this objective, consumers with economic goals will be motivated to make elaborate evaluations of the alternatives. This should, on the one hand, favor online channels, because they offer ready access to information and make comparisons easier. On the other hand, consumers may not need to access large volumes of information about multiple products when they have few items to evaluate, and can evaluate them efficiently in traditional retail settings.

Here again, consumers are likely to choose channels based on whether the product category is functional or hedonic. When the product category is largely hedonic or is both functional and hedonic (as with cell phones and laptops), consumers are likely to prefer the traditional retail stores for this stage, given the difficulty of translating representations of hedonic attributes into the associated experiential benefits.

The economic objective in the third stage of the purchase process (purchase) is to minimize transaction costs and maximize consumption utility. In this stage, the consumer exchanges money for the product. Because of its lower transaction costs and (potentially) lower purchase prices, the consumer is likely to prefer the online channel to the traditional retail channel. That preference, however, is likely to be qualified by positive time discounting, and risk aversion. Positive time discounting (Read \& Loewenstein, 1995) refers to people's preference for immediate consumption (of a positive experience) over delaying it. As items purchased online take some time to arrive, consumers may prefer to buy retail. This is especially likely when the time discounting factor is particularly large. For example, after searching for information on music $\mathrm{CDs}$, and selecting a subset of them for purchase online, a consumer may purchase them at a retail store order to listen to the songs immediately. Likewise, when a consumer seeks to purchase such items as clothing, whose portrayal online may differ in color and texture from the physical product, buying in the retail store reduces risk.

Even when consumers are tightly focused on economic goals, their subgoals at various stages of the purchase process can lead to a shopping sequence distributed across multiple channels. The following vignette captures the experience of one of the consumers we interviewed.

Vignette 2: Anadi Srivastava is looking for a good novel to read on his flight to India. The trip is still a month away, but he likes to plan ahead. As a student living off a fellowship, he is careful about how he spends money. He has recently developed a liking for Indian authors and so, he makes his way to the "International" section at the local Barnes and Nobles bookstore. Soon, he is leafing through The Death of Vishnu by Manil Suri. The blurb for the book promises an entertaining read and Anadi peruses it at some length in the store. Later, when he arrives at his office, Anadi visits Amazon.com. As he expected, a used version of the novel is available there for half the price at the store. He orders it.

Such behavior-browsing for information on one channel and purchasing through another-is increasingly common.

\section{THE QUEST FOR SELF-AFFIRMATION AND CHANNEL CHOICE}

Vignette 3: At the grocery store, Alan Wilkinson walks over to the bin of oranges. The oranges are by and large, similar in shape, size, and color. Yet, Alan carefully inspects each orange, bouncing it gently in his hand, and after smelling the occasional one, places a dozen of them in his basket. He walks away with a satisfied smile.

Choosing oranges in the grocery store allows Alan to bring his orange-selection skills into play, thereby affirming his (subjectively perceived) expertise. This need to maintain positive self-impressions, characterized as the "need for self-enhancement" (Greenwald, Bellezza, \& Banaji, 1988), is a powerful motivator of 
human behavior. This need may manifest itself as a tendency to view oneself as possessing more positive traits than the average person (Brown, 1986), an inclination to attribute successes to self and failures to others (Miller \& Ross, 1975), and a tendency to associate with successful people (Cialdini \& Richardson, 1980). Other consistent behaviors include the tendency to view one's own future as rosier than an objective view would indicate (Lund, 1975), or to perceive greater control over the environment than actually exists (e.g., Langer \& Roth, 1975). A shopping occasion can provide consumers with an opportunity to affirm certain positive or desirable traits. Among the more common traits that consumers seek to affirm are thrift and expertise.

\section{Affirmation of Thrift and Channel Choice}

Thrift is the trait of seeking to acquire products or services inexpensively. Some researchers have suggested that one of the many intangible benefits of using coupons is the affirmation that one has been careful in spending money (Chandon, Wansink, \& Laurent, 2000; Feick \& Price, 1987). Consistent with such theorizing, evidence indicates that consumers who use coupons perceive themselves as smart shoppers; they enhance their overall self-images (Bagozzi, Baumgartner, \& Yi, 1992; Schindler, 1992). How might the objective of self-enhancement through engaging in thrifty behavior influence channel choice? Online channels generally offer greater potential for price comparisons and for finding bargains. However, while the objective value of savings may often be greater online, the perception of thrift can often be greater for purchases in traditional retail stores.

In his self-perception theory, Bem (1972) suggests that individuals examine their own behavior and its attendant circumstances to determine their attitudes towards themselves. In the context of coupon use, for example, this theory suggests that consumers observe the amount of effort and time they expend towards redeeming coupons and draw corresponding inferences regarding personal responsibility-with greater effort and time signaling greater responsibility. Given that buying products on discount in traditional retail stores generally involves more preparation and effort (finding coupons, cutting them out, storing them, remembering to take them to the store and presenting them to the cashier) than it does online (entering a coupon code), shoppers are more likely to perceive themselves as thrifty when using coupons in traditional retail stores (see Dodson, Tybout, \& Sternthal, 1978). Such self-affirmation will likely increase utility from traditional retail shopping, at least among dealprone consumers (cf. Krishna, 1992).

Two caveats are appropriate here. First, consumers' perceptions of themselves as responsible shoppers depend upon their subjective view that using the coupon has resulted in economic gains. Information that online coupons would have provided greater gains, for example, would likely dilute the self-affirming feelings of thriftiness gained by spending time and effort redeeming coupons in a retail store. Likewise, the knowledge that an online source offers much lower prices may overwhelm the self-affirming feeling of thrift associated with effortful shopping and price comparison. For example, buying really cheap, second-hand books at online stores may well be the more attractive option to consumers who seek to affirm their own thriftiness. Second, according to selfperception theory, an external cause for a behavior will undermine attribution to an internal cause. Thus, when consumers redeem coupons because their spouses forced them to, they are less likely to affirm their own qualities of thrift or responsibility, and are more likely to attribute their actions to coercion.

The affirmation of thrift is particularly applicable to the last stage of the purchase process, when consumers purchase particular products from particular sellers. For example, consumers may collect a lot of information online towards forming and pruning their consideration sets, and then spend plenty of effort shopping for the products across stores during the Thanksgiving sales.

\section{Affirmation of Expertise and Channel Choice}

Apart from thrift, shopping expeditions may also affirm consumers' sense of expertise. We use the term expertise to refer to the consumer's perception of being skilled at selecting the best product(s) from a choice set. Researchers see consumer expertise along many dimensions, including subjective expertise and 
objective expertise (Alba \& Hutchinson, 1987; Brucks, 1985). Consumers have objective expertise if they have actual knowledge about the product category in question; they have subjective knowledge if they merely perceive themselves to have such knowledge. While objective expertise generally results in better shopping decisions, subjective expertise is more likely to give them confidence in their decisions, or satisfaction with them (e.g., Brucks, 1985; Sujan, 1985).

People generally consider themselves to be more expert than they actually are, especially in product categories for which it is difficult to objectively determine expertise. For example, unless one truly has expert knowledge about produce, it is difficult to determine which of two randomly chosen baskets of produce is better. Consumers shopping for such goods, therefore, will prefer the channel that provides the greatest opportunity to exercise their perceived expertise.

As the vignette about Alan Wilkinson shopping for oranges illustrates, shoppers have many opportunities to affirm beliefs in their own expertise when they seek products in retail stores where they can touch, smell, and visually inspect the items. Specifically, they can interpret the tactile and other forms of sensory input, which often provide ambiguous information about product quality in a manner that favors their perception of their own expertise. They have a bias similar to the hypothesis-confirmation bias documented by Deighton (1984) and Hoch and Ha (1986). Stated differently, when traditional retail contexts provide consumers with greater opportunities to engage in multisensory assessments than an online context would, they are likely to be more confident that they have selected superior products.

However, traditional retail stores do not always dominate online sites in providing consumers with opportunities for constructing flattering impressions of their own expertise. For example, as opposed to conventional investing through a human broker, online investing may provide investors with greater opportunities to take credit for upward movements of purchased stocks, thus reinforcing their sense of expertise (Konana \& Balasubramanian, in press). Similarly, buying airline tickets online (vs. using travel agents) may contribute to consumers' belief in their own expertise.
To summarize, channels for products and services differ in the opportunities they provide consumers for affirming certain desired perceptions about themselves, such as thrift and expertise. Opportunities for self-affirmation can affect the utility consumers obtain from the instrumental elements of the shopping process, as well as that from the purchased product or service. Such opportunities may be greater in traditional retail channels than in online channels because consumers can exercise their expertise (real or not) in choosing the best items from an assortment. Such opportunities may be greater online, however, when consumers take charge of complex search and purchase processes that were formerly handled by human agents (for example, stock brokers and travel agents). An important qualifier is that consumers vary greatly in their need for self-affirmation. The generalizations described thus far may not apply to those with low need for self-affirmation; such consumers may well, for example, use peapod.com to procure produce.

\section{SYMBOLIC MEANING AND CHANNEL CHOICE}

Vignette 4: Jill Gordon, a senior executive with a telecom firm, is up early in her hotel room in San Antonio, Texas, where she is attending a conference. She has had an exciting, if exhausting schedule at the conference over the last 2 days. She is flying home to Boston at 5:00 p.m. that evening but remembers that she promised to buy a Western outfit for her 11-yearold daughter, Lisa, during her visit. Lisa plans to wear the outfit to a fancy dress competition at school next week and has always wanted a Western outfit. Before she leaves her room for the conference, Jill logs online, searches the Internet, and finds several stores that stock the perfect outfit for Lisa. They all offer next-day delivery to Boston. She considers buying an outfit online, but chooses not to. She hurries through her conference sessions, and is out of the hotel by 2:30 p.m. She visits Katie's Western Wear, her wheeled luggage in tow, spends an hour browsing the racks and putting together a complete Western outfit for Lisa. As the salesperson packs the outfit, Jill cannot help thinking that she could have obtained a similar set of clothing and boots online, yet she is pleased with her decision to visit Katie's. 
Jill compared online and retail shopping and realized that, in terms of process costs, online shopping presented a more attractive proposition. However, the increased effort and involvement in shopping at Katie's translated into a higher utility for the product. What Jill ultimately purchased was not a Western shirt, a silver festooned pair of chaps, denim jeans, a cowhide hat, and a pair of cowboy boots, but a bundle of gifts that captured her love for Lisa. That is, the process of shopping imbued the products with symbolic meaning that transcended their physical attributes (see Figure 1).

\section{Gift Giving as Economic Exchange, Social Exchange, or Agapic Love}

Gift giving is an economically significant activity. The average household in United States spends over $\$ 1,000$ a year on gifts (Horovitz, 2002). Researchers (Belk \& Coon, 1993) have identified three broad categories of meanings associated with gift giving: economic exchange, social exchange, and agapic (selfless) love.

In the economic-exchange perspective, human beings are viewed as cold, analytic social animals devoid of morals, and they give presents to insure that they will receive something more valuable in return (Ekeh, 1974). In the social-exchange perspective, the gift giver hopes to create an emotional bond with the receiver by conveying symbolic meaning through the gift (Belk \& Coon, 1993). In both perspectives, the underlying motive is selfishness (Belk \& Coon, 1993). For the economic gift giver, the selfishness is of a monetary nature. For the social gift giver, the selfishness is of a symbolic nature; the giver seeks increased social indebtedness in return for gifts.

In contrast, in the context of agapic love, the giver gives gifts that are unconstrained and unconstraining (Belk \& Coon, 1993). Such a gift is a pure expression from the heart that does not bind giver and recipient (Carrier, 1991). While agapic love represents a selfless or altruistic motive on the part of the gift giver, economic exchange stands for the exact oppositea cynical motive. Gift giving as social exchangeperhaps responsible for a majority of gifts-lies between these extremes.

\section{Symbolic Meaning in Gift Giving}

How does the quest for symbolic meaning in gift giving influence channel choice? In Jill Gordon's search for a Western outfit, the extra time and effort that she spent selecting the outfit in the retail store imbued the gift with symbolic meaning and increased its utility to Jill, and possibly, even to her daughter. While this seems counterintuitive, the theory of cognitive dissonance (Festinger, 1957) explains why the idea may hold.

According to Festinger, people tend to behave in ways that are consistent with their attitudes because attitude-behavior inconsistencies create an inherently unpleasant feeling state, referred to as dissonance. The theory thus predicts that when people perceive an inconsistency between their attitudes and their behavior, they try to resolve the inconsistency by altering their attitudes to be consistent with their behavior (Cooper, Zanna, \& Taves, 1978) or by altering or reinterpreting their behavior to be consistent with their attitudes (Axsom, 1989).

In the context of social exchange and agapic giftgiving, we may assume that the gift giver harbors positive feelings towards the recipient. This assumption, in conjunction with the finding that individuals generally allocate a greater portion of their available resources (time, effort, and money) to the service of people they like (Tesser, Gatewood, \& Driver, 1968), suggests that consumers will spend more time, effort, or money in procuring a gift than they would a nongift. Indeed, the increased allocation of resources, apart from increasing the utility derived from the process of procuring the gift, may increase the gift's meaning and value, because it serves as a physical manifestation of the extra resources devoted to procuring it.

While increasing the allocation of resources in procuring gifts may enhance utility from the social exchange and agapic perspectives, it may be desirable from an economic-exchange perspective as well. Recipients of gifts are likely to use the (real or imagined) resources allocated to procuring the gifts as indicators of the affection the givers feel for them, as exemplified by the following comment made by one of the people Belk and Coon (1993, p. 203) interviewed: "A gift that 
appears to have been bought in a rush just because it is a birthday is not very valued, it is more of an insult. A gift needs to be personalized or appear as though it took time to find to have its greatest possible value." Economic gift givers are likely to consider such evaluations in determining their courses of action.

Specifically, they are likely to increase the resources they allocate to gifts to enhance the recipients goodwill toward them. In choosing a channel, this means that the giver may prefer the channel that requires the greatest effort, time, and money. In sum, from all three-economic, social exchange, and agapicperspectives of gift-giving, gift givers may prefer traditional channels over online channels when the traditional channels call for greater personal involvement and effort.

This is not to say that online channels are not suitable for procuring gifts: Research firm ComScore projected total 2004 year-end holiday online retail sales of roughly $\$ 15.5$ billion, a $28 \%$ gain over 2003 . However, tracking down and obtaining rare and unique gifts may call for a different kind of effort and perseverance in online versus traditional channels. Online auctioneer eBay is rapidly emerging as a popular gift source. While monitoring and winning auctions can require significant time and effort, many consumers engage in such activities for the thrill of the hunt. Winning an auction on eBay and presenting the item to a relative or a friend is rapidly becoming an appreciated form of gift giving. Further, when symbolic meaning is not important, online shopping tools make it easy to shop for gifts under a budget constraint. For example, consumers can arrange offerings on a seller's Web site in ascending or descending order of price, or can view only items within a certain price range.

A caveat is appropriate here: The economic gift giver is likely to benefit more from the recipient's perception that he or she spent significant resources in procuring the gift, than from the actual expenditure. In fact, for a cynical gift giver, it is optimal to expend the minimum possible resources while maximizing perceived expenditure. Such a strategy could consist of ordering a gift online for delivery to one location (for example, one's office or hotel room) and then transporting it to the recipient. Such a gift giver may prefer online channels.

\section{Symbolic Meaning in Role Playing}

Gift giving is an instance of the general class of activities that provide symbolic meaning through role playing. Other shopping instances with an element of role playing can affect channel choice. In purchasing a bottle for feeding one's infant, for instance, one plays the role of a doting and caring parent. In purchasing the bottle, therefore, the parent may spend more time and effort than necessary to communicate to himself (and to his wife or other onlookers) that he is a good parent. Similarly, shopping for an anniversary card for one's spouse, and thus playing the role of loving husband or wife can provide greater satisfaction with increased effort. In both cases, consumers seeking evidence that they are playing their role in suitable (even exemplary) manners may prefer to shop in channels that require greater time and effort.

In terms of stages of the purchase process, the consumers' quests for symbolic meaning will push them to choose channels that offer the greatest opportunities to expend care and effort in finding the right product. At the first stage, forming the consideration set, consumers can perform detailed searches online and in traditional retail environments. However, consumers may prefer the latter when they want to personally inspect the product. Likewise, in the second stage, selecting an item or items to buy, they can use both channels. It is likely that the deeper the symbolic significance of the gift, the deeper the search within a channel and the broader the search across channels. In the final stage, while purchasing the chosen product, consumers are likely to be driven primarily by economic considerations, because effort expended in choosing a product is more important than its exact price.

\section{SOCIAL INFLUENCES AND EXPERIENTIAL IMPACT}

Vignette 5: Jeanne Milbank returns home after a stressful day at work. Feeling restless, she drives to the downtown mall. Entering Foley's Department Store, she immediately brightens up on seeing the well-lit, inviting shop floor and hearing the soft strains of a piano in the background. She first proceeds to the women's clothing section, where she checks out the new styles on the racks, spending some time on selected items, feeling the texture of the fabrics, and trying 
clothes on before a mirror. She finally picks out a dress she likes and then wanders into the cosmetics section. She chats awhile with the beauty consultant at a display, discussing the latest shades of lipstick and trying out some new perfumes. After buying a bottle of perfume and a new lipstick, she walks quickly through the household appliances section, noting a new electric grill that might make a good Christmas gift. On her way out, she pauses to chat with acquaintances pushing their newborn in a stroller, and offers some advice based on her experience in bringing up her own son Alex. She walks back to her car and returns home, feeling much better and more in control of herself and her environment than when she set out.

In this scenario, Jeanne enjoys the visual, auditory, tactile, and olfactory stimuli of the traditional retail setting and the opportunities for social interaction that it affords. The utility she gains is not tightly linked to the process of shopping; rather, it is associated with the experiential stimuli of the environment (Figure 1).

\section{Social Interactions and Channel Choice}

A salient feature of shopping online is that people almost always do it alone. In contrast, an expected feature of shopping in traditional retail settings is the presence of others. This difference affects the utility consumers derive from shopping activities and from the products they purchase.

First, for embarrassing purchases such as pornography or contraceptives, consumers may prefer online channels to avoid such negative emotions as shame or guilt. The success of online pornographic sites is consistent with this view, as is the finding that investors prefer online brokers (for example, Ameritrade or $\mathrm{E}$ *trade) to human brokers for transacting their speculative trades or for trading in small amounts to avoid potential embarrassment (Konana \& Balasubramanian, in press).

For other purchases, however, the presence of others during shopping may increase utility. Raghunathan and Corfman (2004) found that the perception of congruity between one's own opinions (say, of a movie or a piece of clothing) and those of others leads to positive feelings. They found that people generally desire the presence of others because it provides opportunities for creating and maintaining human bonds (which is a pleasurable experience) or enhancing the veridicality of one's opinions (which is diagnostic for making better future decisions). Since during first meetings, two or more individuals typically engage in small and polite talk (Berger \& Calabrese, 1975), strangers interacting are likely to express congruent opinions enhancing their enjoyment during shopping.

Interestingly, people do not need to converse with others to perceive interpersonal congruence in opinions; in the absence of information to the contrary, people tend to believe that others' opinions and attitudes are similar to their own-an effect termed false consensus (Goethals, Allison, \& Frost, 1979). Hence, being in the presence of others, including strangers, may increase people's enjoyment of shared experiences even if they hold dissimilar opinions (as long as they do not articulate them).

These arguments may not hold in some cases. First, noncompliant individuals (Cohen, 1967) and those with little need for accuracy (Trope, 1975) may derive no utility from the presence of others. Such individuals get little satisfaction from creating human bonds or from affirming the accuracy of their opinions (Raghunathan \& Corfman, 2004). Thus, their channel choices may be driven by factors other than the opportunity for social interactions. In fact, consumers who are particularly averse to social interactions may prefer shopping online.

On the other hand, virtual communities on the Internet offer consumers the opportunity to socialize anonymously. The challenge to sellers, though, is to obtain profitable economic leverage from the virtual community's social base (Balasubramanian \& Mahajan, 2001). That is, consumers may socialize within a virtual community the seller provides, but make their purchases elsewhere. Retail stores face the same challenge: consumers may shop in retail stores but buy elsewhere.

When consumers are driven to socialize, their personalities may influence their channel choices. Those who seek anonymous socialization will use the Internet, whereas those who seek open, physical socialization will use traditional retail settings. Both are likely to choose their channels for final purchase 
based on economic grounds. They may navigate among channels during the purchase sequence. For example, social consumers may visit malls and form consideration sets as they socialize. However, they may finally purchase from sellers who offer the lowest prices.

\section{Experiential Impact and Channel Choice}

Traditional retail stores permit rich, multimedia experiences that can involve all five senses and inspire thoughts and feelings that can produce a range of psychological and behavioral outcomes (Bitner, 1992; Raghunathan, \& Irwin, 2001; Schmitt, 1999). Whereas online channels may include atmospheric cues (Eroglu, Machleit, \& Davis, 2001), they currently provide relatively impoverished sensory experiences (e.g., Schmitt, 1999; Schmitt \& Simonson, 1997). How does this difference affect channel choice?

Research suggests that people seek greater stimulation when understimulated, and tranquility when overstimulated (Bryant \& Zillman, 1984; Raju, 1980). To the extent that experientially rich environments provide greater stimulation, consumers who are understimulated at the time or generally desire high levels of stimulation will prefer traditional retail environments. In contrast, consumers who are already overloaded with stimuli or seek low levels of stimulation will prefer more serene online shopping contexts. Menon and Kahn (2002) found that consumers already exposed to a highly stimulating Web site tended to seek less arousing activities.

Balancing the increased stimulation offered by traditional retail channels is the potential for attaining flow states (Csikszentmihalyi, 1997) in online channels. When online channels organize and sequence stimuli in a way that does not overwhelm shoppers, but instead offer a seamless sequence of responses facilitated by machine interactivity, they can find the process of searching for, locating, and procuring products online enjoyable (Hoffman \& Novak, 1996). In fact, online channels can facilitate such flow for both task-oriented and experiential activities (Novak, Hoffman, \& Duhachek, 2003).

The visual aspects of the channel also influence how and what consumers buy. Visual cues are powerful memory aids. Researchers have argued that people memorize information as visual or episodic traces, rather than as semantic bits (Biel, 1993; Coulter, Zaltman, \& Coulter, 2001). Thus, presenting information visually_or more generally, in a multisensory fashion-may help people to assimilate it and associate it with other information in memory (Bower, 1981). Channels differ greatly in terms of information presentation. Peapod.com, for example, lists grocery items by semantic category putting milk and yogurt under dairy products, and fruits and vegetables under produce. Although traditional grocery stores use the same categories to display products, they provide multisensory experiences. Shoppers see products in three dimensions, touch them, and smell them.

When a shopping trip results in many unplanned purchases, as is often the case for groceries (Kahn \& Schmittlein, 1992), multisensory displays products may jog the consumers' memories. For example, a shelf of pasta sauce may cue the purchase of pasta or even tomatoes. Further, traditional retail channels can increase the likelihood that shoppers will make impulsive purchases because multisensory displays are typically more attractive and harder to resist than verbal descriptions (Shiv \& Fedorokhin, 1999). The possibility of stumbling upon new and interesting products while walking the aisles gives the shopper a sense of discovery and adventure. On the flip side, keeping within a budget and avoiding impulse buying is easier when shopping online (Razzi, 2000). Consequently, shoppers who tend to overbuy in retail stores may prefer online channels. Therefore, while the experiential richness of the traditional retail channel mainly affects the noninstrumental elements of the purchase process, to a limited extent, such richness can affect some instrumental elements as well.

When it is important to experience products, the traditional retail channel is likely to figure early in the purchase process. In the first stage, consumers seek knowledge about product attributes, their importance and levels across different products, and details of design and styling that are best experienced visually. Even at this stage, the growing technological capabilities of online channels may enable sellers to provide consumers with rich experiences. Schlosser (2003) finds that object interactivity (the ability to directly manipulate objects in a virtual world-for example, to press the buttons of a virtual camera) increases 
consumers' purchase intentions regardless of whether they were seeking an aesthetic experience (browsing) or specific product-related information (searching).

Further searching for information on product ratings is best conducted online. Experiential cues help shoppers to form consideration sets; however for standard products, they will likely choose purchase outlets based solely on economic considerations-either online or in a retail store.

\section{SHOPPING SCHEMAS AND SCRIPTS}

Vignette 6: It's 6.30 a.m. on a Saturday morning. John Mason, a 63-year-old widower, wakes up to his trusted alarm. He stretches and shuffles to the bathroom. At exactly 7.00 a.m., a freshly shaved and showered John goes downstairs, picks up his newspaper, and pours himself a cup of automatically brewed coffee. He sits at his breakfast table, reads the news headlines, and then opens the coupons insert. He cuts a few coupons out and sorts them in his coupon organizer. At 8.00 a.m., John walks out to the garage, gets in his car and drives to the grocery store on his weekly shopping trip. He has shopped in the same store for years. He is pleased to find his favorite parking spot available at that early hour. He enters the store and walks the aisles that seem like a second home to him. He is disconcerted to see that the apples and bananas have switched places-he pauses to take this in. Shopping done a half-hour later, he proceeds to Susan Dillinger's checkout line. Her line is longer than the others, but John chooses it anyway. As Susan checks out the groceries and credits his coupons, they chat about her two boys and their Little League games, which he has followed with her for the past several weeks. He loads the groceries into his car and drives, as always, to the gas station down the road to fuel up and buy two tickets for the weekly Lotto drawing. He then drives home. His Saturday morning feels complete.

Shopping can be a matter of routine, and even ritual. When consumers follow established shopping schemas and scripts in employing a channel, they rarely use alternative channels to compare costs and benefits. A wealth of research concerns how consumers make decisions in these settings (for a review, see Bettman, Johnson, \& Payne, 1991). While researchers have debated the extent and manner of consumer information processing, they assume that the consumer choice task involves some comparison of alternatives. This is appropriate when consumers do choose between competing offerings. When consumers patronize a channel because it figures in some schema that characterizes the consumer's life or some script that runs through it, this standard decision scenario may not apply.

\section{Schema-Based Channel Choice}

Bettman (1979) defines a schema as an organized pattern of expectations for a stimulus domain. Schemas facilitate top-down, conceptually driven processing; individuals applying schemas rely on preexisting knowledge rather than new information (Abelson, 1981).

How would shopping figure in a schema? And does grocery shopping fall naturally and unequivocally into a single schema? We cannot define many everyday activities precisely and universally. Grocery shopping can be variously classified as a chore, a time-filler, a duty, a pleasurable outing, or a project that must be evaluated in terms of economic costs and benefits. Categorization is important because, one "cannot apply a schema without first having categorized the stimulus, and the process of categorization itself is of considerable interest" (Fiske \& Taylor, 1991, p. 105).

In vignette 6 , John Mason considers shopping to be a well-defined, recurring situation. The corresponding schema controlled John's Saturday morning itself: rising to the alarm, scanning the paper, clipping coupons, driving to the store, finding his favorite parking spot, filling his cart, paying for his groceries, chatting with Susan, proceeding to fill his gas tank and buy Lotto tickets, and finally driving back home. Such a categorization contrasts strongly with the one invoked by a consumer seeking efficient shopping: This consumer would classify shopping as a project with economic costs and returns. Such a consumer would choose a time, place, and manner of shopping to minimize the time, effort, and money spent. For John, the time, place and manner of shopping are given, and help define his concept of Saturday morning.

More formally, we can view the activities that constitute John's Saturday morning as attributes of the grocery shopping stimulus domain arranged in an 
established temporal order. The natural structure of the activities imposes some of this order (John must shop before he pays). John has developed other aspects of this order over time and he can, but rarely does violate (he could fill up at the gas station before he shops at the grocery store, but he never does). Stated differently, John plays out his Saturdays to a script that he has developed over time. We can define a script as a schema characterized by temporal ordering of its component actions (Smith \& Houston, 1985).

By invoking schemas, consumers alter their responses to external stimuli that could influence their agendas, the constraints they use in selecting or eliminating choice alternatives. As Hauser (1986) demonstrated, different agendas lead to different choices. By invoking a schema, a consumer would likely activate an agenda that involves top-down, concept-driven processing, rather than bottom-up, data-driven processing. Such a consumer would have little opportunity to process information following a rigorous, algebraic model that requires evaluating the traits of all available alternatives in isolation and then combining those evaluations to obtain overall evaluations of the alternatives (Anderson, 1981). For example, as described below, John Mason, our Saturday morning shopper, and Jake, who flits regularly across channels searching for the best buy, respond differently to a coupon they receive in the mail for a $\$ 5$ discount on a bottle of wine that both buy regularly.

Sequence 1 (John): Receives coupon $\rightarrow$ Considers the magnitude of the savings $\rightarrow$ Thinks about using it the coming Saturday morning $\rightarrow$ Finds out whether it is applicable in the retail store $\rightarrow$ Decides to keep it and use it if it is usable in the retail store; if not, he throws it away.

Sequence 2 (Jake): Receives coupon $\rightarrow$ Considers the magnitude of the savings $\rightarrow$ Checks where the coupon is applicable $\rightarrow$ Thinks about the costs and benefits of shopping for wine in competing channels (with the use of the coupon in one channel) $\rightarrow$ Chooses the best channel.

John thinks about whether he can use the coupon at his grocery store on the Saturday morning; the coupon has no influence on his choice of channel.
Jake, in contrast, evaluates competing channels, and the coupon influences his choice of channel.

As schemas and scripts can influence individual channel choices, so can shopping rituals. For example, consider a busy family who shops at the local farmer's market every Saturday morning. This weekly outing gives the family members an opportunity to spend time together. Rook (1984, p. 282) notes that "within a family, [such] ritual practices cement relationships and foster joint participation in numerous household activities." Further, the family's visit to the farmer's market can embed all four common elements of rituals that Rook (1985) demarcated: actor-participants (the family members), an audience (for each member of the family, the other members serve as an audience; for the family as a unit, the sellers and other shoppers from the community serve as an audience); scripted, episodic behavior (all the family members reserve Saturday mornings for shopping); and ritual artifices (the home-baked rye and pumpernickel bread they buy from the Hogan Farm stall every week).

Scripts and schemas for online shopping have emerged recently. While families or other socializing groups may follow the scripts and schemas associated with traditional retail shopping, individuals may follow those for online shopping. Sometimes, individuals' online shopping behaviors may be compulsive or border on addictive: "Take the thrill of gambling, the excitement of computer games, the enjoyment of collecting, and the desire to get a good deal, and sprinkle it with a little of the old hunter-gatherer instinct. Suddenly, you've got several million people hooked on the online auctions" ("Internet Auctions Can," 1999, p. 1A).

When consumers are guided by a schema or a script in shopping, they are unlikely to employ distinct channels at the various stages of the shopping process. Because moving between channels means changing contexts, scripts and schemas for shopping typically play out within one channel. However, consumers could use multiple channels in shopping for a product or service category, but follow a schema or script in one of those channels. For example, Konana and Balasubramanian (in press) found that online investors typically partitioned their portfolios into an 
online component that they managed through an online broker, and a second component that they managed through a human broker. Many of these investors exhibited scripted behavior that bordered on day trading with respect to their online portfolios, including checking the status of their stocks frequently (for example, on arriving at work, before and after lunch, and before departing from work) and they often moved in and out of stock positions based on such information. They managed the stocks they held with the human broker differently and in a less scripted manner, with a less-speculative, long-term outlook.

\section{CONCLUSION}

In our conceptual framework focusing on product- and process-related utility, we synthesized existing insights and developed new insights that help explain consumers' channel choices in a multichannel environment. The framework yields research and managerial implications that are not available from a pure efficiency-based view of channel choice.

\section{Research Implications}

Our framework provides a platform for research on channel choice in the multichannel environment. By positing how five consumer goals drive the utility they derive from the purchase process and the purchased products, we developed a richer conceptualization of channel choice at various stages of the purchase process than those available in the existing literature.

First, to further understand consumer behavior in the multichannel environment, we need a detailed understanding of how consumer goals at various stages of the decision process are in accord with the characteristics of various channels. The goals and the relevance of specific channel characteristics may differ according to product or service category, the consumer's experience and knowledge of the category, and the consumer's preferences for information-presentation formats. Because of these factors, we expect that developing a single theory that captures consumer behavior in the multichannel environment will be challenging. We expect that future work in the area will lean towards contingency frameworks and empirical generalizations.

Second, researchers must pay attention to how the channel processes consumers employ in searching for information, building knowledge, comparing and choosing among alternatives, and executing transactions provide them with opportunities for selfaffirmation. For example, since redeeming coupons in traditional channels typically takes greater time and effort, the shoppers have a stronger opportunity to self-affirm their thriftiness. Specific shopping procedures associated with a channel may also affirm shoppers' sense of expertise in product selection.

Third, in analyzing how consumers shop for products with symbolic meaning, researchers must be sensitive to how consumers value the shopping effort they expend. In particular, spending greater time and effort procuring a gift may enhance the satisfaction they obtain from the product, and from the purchase process. Likewise, consumers may prefer the channel that entails greater search costs and effort for purchases that involve role-playing (such as those of a good father or loving wife).

Fourth, researchers must consider how the distinct physical environments associated with online and traditional retail shopping influence consumers' preferences for channels and their behavior within them. Likewise, to fully understand why consumers prefer a specific channel in a given situation, researchers must consider their motivations to seek sensory stimulation and to share experiences with others. Further, researchers must pay careful attention to how consumers gather and process information in each channel. For example, the rich, multisensory display of information in traditional retail channels may facilitate these tasks.

Finally, to study schema- or script-based channel use, researchers must focus anew on the role the shopping expedition plays in the consumer's life and the role retail stores play in the consumer's construction of reality. Consistent with this argument, the following issues remain under-researched: the drivers of customer store choice and loyalty, the part played by the store in the customer's daily or weekly life cycle, and the role of the traditional retail sector in supporting 
socialization at the family level (Peterson \& Balasubramanian, 2002).

Overall, we found that a pure economic view of channel choice and use is likely to be incomplete. Researchers must consider the psychological biases and goals consumers invoke in using specific channels.

\section{Managerial Implications}

Our analysis yielded some insights for marketing managers. First, managers should develop detailed knowledge about consumer shopping sequences within their product or service categories. Without knowing how consumers construct their goals at various stages of the shopping process and how they choose channels in seeking those goals, managers have little ability to influence their choice of channels and sellers. Such knowledge is particularly important for managers of channels that consumers use in forming their consideration sets, but drop before making their purchases. Managers may find technology-intensive tools to influence consumers channel choices. The electronics retailer Best Buy offers buyers "Reward Zone" cards for accumulating points on purchases that can be redeemed for discounts. Best Buy could set up card readers near product displays so shoppers could swipe their cards to indicate their interest in that category and in obtaining further information online (for example, via e-mail). Best Buy could thus ensure that it did not lose these customers.

Second, when self-affirmation is important to consumers, channel managers should provide affirming feedback. For example, online investors see rapid feedback on their orders as a sign that they control the trading process (Barber \& Odean, 2001). Likewise, sellers' feedback regarding how much shoppers saved compared to prices at other outlets can self-affirm their perceptions of thriftiness. In one grocery chain, for example, the cashiers tell shoppers how much they saved by using the grocery card.

Third, channel managers should provide shoppers with opportunities to realize symbolic meaning, especially when they are shopping for gifts or playing roles. The manager of an online toy store may find such messages as "toys carefully chosen by a group of mothers" or "toys shown by research to promote learning and safety" more effective than "quick and convenient shopping for your kid's toys." Such efforts are particularly important when the channel does not provide symbolic meaning or facilitate role-playing. Online retailers of distinctive gifts could elaborate on their product histories, their characteristics, the efforts made to locate the items, and the rigorous criteria used to select offerings. The consumers may then feel confident that they have found suitable gifts.

Fourth, although traditional retail channels are richer sensory environments than online stores, the managers of online channels have great flexibility in configuring the shopping environment. They can develop a menu of stimuli-intensive and stripped-down versions of their shopping sites that consumers can choose from. Many online retailers provide shoppers with customized pages based on their past behavior and preferences and with text-only versions of their Web sites. Web developers are working to maintain graphic versions of Web content and to generate textonly versions on demand.

Channel managers should remember that many consumers shop to integrate social and economic goals. Traditional retail shopping naturally accommodates social interactions. Online managers could facilitate similar interactions by promoting virtual communities. However, few virtual communities have succeeded in the commercial context. Such communities work best when their commercial processes are embedded within their social processes, an outcome termed as "economic $\rightarrow$ social grafting" (Balasubramanian \& Mahajan, 2001, p. 128). The success of such virtual communities may partly depend on their product or service category. Sellers of environmentally friendly products might succeed in hosting free form virtual communities, while Amazon.com controls and channels its members' input into product reviews.

Finally, when people use a channel because of shopping schemas or scripts, messages highlighting the economic benefits of alternative channels may not change their choice. Rather, managers of alternative channels should try to either break or work with the consumers' existing schemas or scripts, for example, by promising consumers substantial reward for their first use of the alternative channel. From a practical standpoint, it is difficult to determine which 
consumers follow scripts. Managers could target consumers based on demographic variables that co-vary with schema and script usage, and with other routinized behavior. For example, since the elderly are prone to using scripts, managers could target residents of retirement communities with rewards for breaking their existing scripts that may favor a rival channel format.

\section{Limitations and Future Research}

Our research has two key limitations that can be addressed in future research. First, our model clearly does not capture the entire range of social, psychological, and economic issues that relate to products, processes, and their interactions. Our model is a beginning. Likewise, Konana and Balasubramanian (in press) take an early step in this direction by proposing a social-economic-psychological (SEP) model of technology adoption and usage. Much more remains to be done in this context. We hope other researchers can enrich the model by incorporating the missing variables and relationships.

Second, although our framework provides a conceptual understanding of issues based on synthesizing the existing literature and interviewing customers, it has not been empirically tested. Many of our insights can be tested using either survey-based or experimental approaches.

\section{REFERENCES}

Abelson, R.P. (1981). Psychological Status of the Script Concept. American Psychologist, 36(7), 715-729.

Alba, J., Lynch, J., Weitz, B., Janiszewski, C., Lutz, R., Sawyer, A., et al. (1997). Interactive Home Shopping: Consumer, Retailer, and Manufacturer Incentives to Participate in Electronic Marketplaces. Journal of Marketing, 61, 38-53.

Alba, J., \& Hutchinson, W.J. (1987). Dimensions of Consumer Expertise. Journal of Consumer Research, 13, 411-454.

Anderson, N.H. (1981). Foundations of Information Integration Theory. New York: Academic Press.

Ariely, D. (2000). Controlling the Information Flow: Effects on Consumers' Decision Making and Preferences. Journal of Consumer Research, 27(2), 233-248.

Axsom, D. (1989). Cognitive Dissonance and Behavior Change in Psychotherapy. Journal of Experimental Social Psychology, 25, 234-252.
Bagozzi, R., Baumgartner, H., \& Yi, Y. (1992). State Versus Action Orientation and the Theory of Reasoned Action: An Application to the Coupon Usage. Journal of Consumer Research, 18, 505-518.

Bakos, Y. (1991). A Strategic Analysis of Electronic Marketplaces. MIS Quarterly, 15, 295-310.

Bakos, Y. (1997). Reducing Buyer Search Costs: Implications for Electronic Market-Places. Management Science, 43(12), 1676-1692.

Balasubramanian, S. (1998). Mail Versus Mall: A Strategic Analysis of Competition Between Direct Marketers and Conventional Retailers. Marketing Science, 17, 181-195.

Balasubramanian, S., \& Mahajan, V. (2001). The Economic Leverage of the Virtual Community. International Journal of Electronic Commerce, 5(3), 103-138.

Balasubramanian, S., Konana, P., \& Menon, N. (2003). Customer Satisfaction in Virtual Environments: A Study of Online Investing. Management Science, 49(7), 871-889.

Barber, B.M., \& Odean, T. (2001). The Internet and the Investor. Journal of Economic Perspectives, 15(1), 41-54.

Belk, R., \& Coon, G.S. (1993). Gift Giving as Agapic Love: An Alternative to the Exchange Paradigm Based on Dating Experiences. Journal of Consumer Research, 20, 393-417.

Bem, D.J. (1972). Self-Perception Theory. In L. Berkowitz (Ed.), Advances in Experimental Social Psychology (pp. 1-62). New York: Academic Press.

Berger, C.R., \& Calabrese, R.J. (1975). Some Explorations in Initial Interaction and Beyond: Toward a Developmental Theory of Interpersonal Communication. Human Communication Research, 1, 99-112.

Bettman, J.R. (1979). An Information Processing Theory of Consumer Choice. Reading, MA: Addison-Wesley.

Bettman, J.R., Johnson, E.J., \& Payne, J.W. (1991). Consumer Decision Making. In T.S. Robertson \& H.H. Kassarjian (Eds.), Handbook of Consumer Behavior (pp. 50-84). Englewood Cliffs, NJ: Prentice-Hall.

Biel, A.L. (1993). Converting Image Into Equity. In D.A. Aaker \& A.L. Biel (Eds.), Brand Equity and Advertising: Advertising's Role in Building Strong Brands (pp. 67-82). Hillsdale, NJ: Lawrence Erlbaum.

Bitner, M.J. (1992). Servicescapes: The impact of Physical Surroundings on Customers and Employees. Journal of Marketing, 56(2), 57-71.

Bower, G.H. (1981). Mood and Memory. American Psychologist, 36(2), 129-148.

Brown, J.D. (1986). Evaluations of Self and Others: SelfEnhancement Biases in Social Judgments. Social Cognition, 4(4), 353-376.

Brucks, M. (1985). The Effects of Product Class Knowledge on Information Search Behavior. Journal of Consumer Research, 12, 1-16. 
Bryant, J., \& Zillman, D. (1984). Using Television to Alleviate Boredom and Stress: Selective Exposure as a Function of Induced Excitational States. Journal of Broadcasting, 28(1), 1-20.

Brynjolfsson, E., \& Smith, M. (2000). Frictionless Commerce? A Comparison of Internet and Conventional Retailers. Management Science, 46(4), 563-585.

Carmon, Z., \& Simonson, I. (1998). Price-Quality Trade-Offs in Choice Versus Matching: New Insights Into the Prominence Effect. Journal of Consumer Psychology, 7(4), 323-343.

Carrier, J.G. (1991). Gifts in a World of Commodities: The Ideology of the Perfect Gift in American Society. Social Analysis, 19, 19-37.

Chandon, P., Wansink, B., \& Laurent, G. (2000). A Benefit Congruency Framework of Sales Promotion Effectiveness. Journal of Marketing, 65, 65-81.

Cialdini, R.B., \& Richardson, K.D. (1980). Two Indirect Tactics of Image Management: Basking and Blasting. Journal of Personality and Social Psychology, 39, 406-415.

Cohen, J.B. (1967). An Interpersonal Orientation to the Study of Consumer Behavior. Journal of Marketing Research, 4, 270-278.

Colquitt, J.A. (2001). On the Dimensionality of Organizational Justice: A Construct Validation of a Measure. Journal of Applied Psychology, 86, 386-400.

Cooper, J., Zanna, M.P., \& Taves, P.A. (1978). Arousal as a Necessary Condition for Attitude Change Following Induced Compliance. Journal of Personality and Social Psychology, 36(10), 1101-1106.

Coulter, R.A., Zaltman, G., \& Coulter, K.S. (2001). Interpreting Consumer Perceptions of Advertising: An Application of the Zaltman Metaphor Elicitation Technique. Journal of Advertising, 30(4), 1-21.

Csikszentmihalyi, M. (1997). Finding Flow: The Psychology of Engagement With Everyday Life. Chicago: Perennial Press.

Degeratu, A.M., Rangaswamy, A., \& Wu, J. (2000). Consumer Choice Behavior in Online and Traditional Supermarkets: The Effects of Brand Name, Price, and Other Search Attributes. International Journal of Research in Marketing, 17, 55-78.

Deighton, J. (1984). The Interaction of Advertising and Evidence. Journal of Consumer Research, 11(3), 763-770.

Dodson, J.A., Tybout, A.M., \& Sternthal, B. (1978). Impact of Deals and Deal Retraction on Brand Switching. Journal of Marketing Research, 25, 72-81.

Ekeh, P.P. (1974). Social Exchange Theory: The Two Traditions. Cambridge, MA: Harvard University Press.

Eroglu, S.A., Machleit, K.A., \& Davis, L.M. (2001). Atmospheric Qualities of Online Retailing: A Conceptual Model and Implications. Journal of Business Research, 54(2), 177-184.
Evans, P., \& Wurster, T.S. (1997, Sep-Oct). Strategy and the new economics of information. Harvard Business Review, 71-82.

Feick, L., \& Price, L. (1987). The Market Maven: A Diffuser of Marketplace Information. Journal of Marketing, 51(1), 83-97.

Festinger, L. (1957). A Theory of Cognitive Dissonance. Palo Alto, CA: Stanford University Press.

Fischer, G.W., Carmon, Z., Ariely, D., \& Zauberman, G. (1999). Goal-Based Construction of Preference: Task Goals and the Prominence Effect. Management Science, 45, 1057-1075.

Fiske, S.T., \& Taylor, S.E. (1991). Social cognition. New York: McGraw-Hill.

Goethals, G.R., Allison, S.J., \& Frost, M. (1979). Perceptions of the Magnitude and Diversity of Social Support. Journal of Experimental Social Psychology, 15(6), $570-581$.

Greenwald, A.G., Bellezza, F.S., \& Banaji, M.R. (1988). Is Self-Esteem a Central Ingredient of the Self-Concept? Personality and Social Psychology Bulletin, 14(1), 34-45.

Hauser, J.R. (1986). Agendas and Consumer Choice. Journal of Marketing Research, 2, 199-212.

Hoch, S.J., \& Ha, Y. (1986). Consumer Learning: Advertising and the Ambiguity of Product Experience. Journal of Consumer Research, 13, 221-233.

Hoffman, D., \& Novak, T.P. (1996). Marketing in Hypermedia Computer Mediated Environments: Conceptual Foundations. Journal of Marketing, 60(3), 50-68.

Horovitz, B. (2002, November 20). Strapped Americans trim Gift Spending. USA Today, p. A01.

Internet Auctions Can Fulfill Passions. (1999, March 10). USA Today, p. 1A.

Kahn, B.E., \& Schmittlein, D.C. (1992). The Relationship Between Purchases Made on Promotion and Shopping Trip Behavior. Journal of Retailing, 68(3), 294-315.

Kang, S., Zimmerman, A., \& Byron, E. (2004, December 27). MasterCard Sees Solid Rise of $8.1 \%$ in Holiday Spending. The Wall Street Journal, p. B1.

Konana, P., \& Balasubramanian, S. (in press). The Social-Economic-Psychological (SEP) Model of Technology Adoption and Usage: An Application to Online Investing. Decision Support Systems.

Krishna, A. (1992). The Effect of Deal Knowledge on Consumer Purchase Behavior. Journal of Marketing Research, 31(1), 76-91.

Langer, E.J., \& Roth, J. (1975). Heads I Win, Tails It's Chance: The Illusion of Control as a Function of the Sequence of Outcomes in a Purely Chance Task. Journal of Personality and Social Psychology, 32(6), 951-955.

Lilien, G.L., Kotler, P., \& Moorthy, S.K. (1992). Marketing Models. Englewood Cliffs, NJ: Prentice-Hall. 
Lund, F.H. (1975). The Psychology of Belief: A Study of Its Emotional and Volitional Determinants. Journal of Abnormal and Social Psychology, 20, 63-81.

Menon, S., \& Kahn, B.E. (2002). Cross-Category Effects of Induced Arousal and Pleasure on the Internet Shopping Experience. Journal of Retailing, 78(1), 31-40.

Miller, D.T., \& Ross, M. (1975). Self-Serving Biases in the Attribution of Causality: Fact or Fiction? Psychological Bulletin, 82(2), 213-225.

Nedungadi, P. (1990). Recall and Consumer Consideration Sets: Influencing Choice Without Altering Brand Evaluations. Journal of Consumer Research, 17(3), 263-276.

Novak, T.P., Hoffman, D.L., \& Duhachek, A. (2003). The Influence of Goal-Directed and Experiential Activities on Online Flow Activities. Journal of Consumer Psychology, 13(1\&2), 3-16.

Nowlis, S.M., \& Simonson, I. (1997). Attribute-Task Compatibility as a Determinant of Consumer Preference Reversals. Journal of Marketing Research, 34(2), 205-218.

Peterson, R.A., \& Balasubramanian, S. (2002). Retailing in the 21st Century: Reflections and Prognosis. Journal of Retailing, 78(1), 9-16.

Peterson, R.A., Balasubramanian, S., \& Bronnenberg, B.J. (1997). Exploring the Implications of the Internet for Consumer Marketing. Journal of the Academy of Marketing Science, 25, 329-346.

Raghunathan, R. (2004). Stage of Purchase Decision as a Determinant of Decision Rules. Working Paper, The University of Texas at Austin, Austin, TX.

Raghunathan, R., \& Corfman, K.P. (2004). Is Happiness Shared Doubled and Sadness Shared Halved?: Social Influence on Enjoyment of Pleasant and Unpleasant Experiences. Working Paper, The University of Texas at Austin, Austin, TX.

Raghunathan, R., \& Irwin, J.R. (2001). Walking the Hedonic Product Treadmill: Default Contrast And MoodBased Assimilation Effects in Judgments of Predicted Happiness With Target Product. Journal of Consumer Research, 28(3), 355-368.

Raju, P.S. (1980). Optimum Stimulation Level: Its Relationship to Personality, Demographics, and Exploratory Behavior. Journal of Consumer Research, 7(3), 272-282.

Razzi, E. (2000, November). Retailer's Siren Song. Kiplinger, 12-15.

Read, D., \& Loewenstein, G. (1995). Diversification Bias: Explaining the Discrepancy in Variety Seeking Between Combined and Separated Choices. Journal of Experimental Psychology: Applied, 1(1), 34-49.
Rook, D.W. (1984). Ritual Behavior and Consumer Symbolism. In T.F. Kinnear (Ed.), Advances in Consumer Research (Vol. 11, pp. 279-284). Provo, UT: Association for Consumer Research.

Rook, D.W. (1985). The Ritual Dimension of Consumer Behavior. Journal of Consumer Behavior, 12, 251-264.

Schindler, R.M. (1992). A Coupon Is More Than a Low Price: Evidence From a Shopping-Simulation Study. Psychology and Marketing, 9(6), 431-451.

Schlosser, A.E. (2003). Experiencing Products in the Virtual World: The Rule of Goal and Imagery in Influencing Attitudes Versus Purchase Intentions. Journal of Consumer Research, 30,184-198.

Schmitt, B. (1999). Experiential Marketing. New York: The Free Press.

Schmitt, B., \& Simonson, A. (1997). Marketing Aesthetics. New York: The Free Press.

Sen, A. (1997). Maximization and the Act of Choice. Econometrica, 65(4), 745-779.

Shankar, V., Smith, A.K., \& Rangaswamy, A. (2003). Customer Satisfaction and Loyalty in Online and Offline Environments. International Journal of Research in Marketing, 20, 153-175.

Shiv, B., \& Fedorikhin, A. (1999). Heart and Mind in Conflict: The Interplay of Affect and Cognition in Consumer Decision Making. Journal of Consumer Research, 26(3), 278-292.

Shiv, B., \& Huber, J. (2000). The Impact of Anticipating Satisfaction on Consumer Choice. Journal of Consumer Research, 27(2), 202-216.

Smith, R.A., \& Houston, M.J. (1985). A Psychometric Assessment of Measures of Scripts in Consumer Memory. Journal of Consumer Research, 12, 214-224.

Sujan, M. (1985). Consumer Knowledge: Effects on Evaluation Strategies Mediating Consumer Judgments. Journal of Consumer Research, 12, 31-46.

Svenson, O. (1979). Process Descriptions of Decision Making. Organizational Behavior and Human Decision Processes, 23(1), 86-112.

Tesser, A., Gatewood, R., \& Driver, M. (1968). Some Determinants of Gratitude. Journal of Personality and Social Psychology, 9(3), 233-236.

Trope, Y. (1975). Seeking information about one's own ability as a determinant of choice among tasks. Journal of Personality and Social Psychology, 32, 1004-1013.

West, P.M., Brown, C.L., \& Hoch, S.J. (1997). Consumption Vocabulary and Preference Formation. Journal of Consumer Research, 23(2), 120-135. 